Gut, 1986, 27, 1147-1150

\title{
Influence of sham feeding on salt and water absorption in the human jejunum
}

\author{
G R BARCLAY AND L A TURNBERG \\ From the Department of Medicine, Hope Hospital, (University of Manchester School of Medicine), Salford, \\ Manchester.
}

SUMmARY Vagal stimulation induced by sham feeding in 11 healthy subjects was used to examine the possibility that the autonomic nervous system might be involved in the control of human jejunal absorption. Gastric acid secretion was measured from gastric aspirates corrected for recovery, and jejunal absorption was determined using a triple lumen perfusion technique. Sham feeding induced a significant increase in gastric acid secretion from 1.29 to $7.73 \mathrm{mmol} / \mathrm{h}(\mathrm{p}<0.02)$. Jejunal absorption of water decreased significantly from 41.0 to $26.8 \mathrm{ml} / 30 \mathrm{~cm} / \mathrm{h}(\mathrm{p}<0.02)$, sodium from 2.60 to $0.74 \mathrm{mmol} / 30 \mathrm{~cm} / \mathrm{h}(\mathrm{p}<0.05$, and chloride from 2.68 to $0.74 \mathrm{mmol} / 30 \mathrm{~cm} / \mathrm{h}$ $(\mathrm{p}<0.02)$. During the hour after sham feeding gastric acid secretion and jejunal absorption returned towards basal values. These results suggest that vagal stimulation may have influenced jejunal absorption of salt and water in man and supports the possibility that the autonomic nervous system has a physiological role in the control of intestinal mucosal function.

The possibility that the autonomic nervous system may be involved in the control of intestinal transport of salt and water has been raised by several observations. Cholinergic agonists stimulate secretion in vitro and in vivo in the human small intestine while adrenergic agonists enhance absorption. ${ }^{1-3}$ Cholinergic and adrenergic binding receptors have been demonstrated on intestinal epithelial cells supporting the possibility that these agonists have a physiological role in the control of epithelial function. ${ }^{4}$ The influence of physiological stimulation exerted via the autonomic nervous system on transport has received little attention. In this paper we describe the effects of vagal stimulation, induced by sham feeding, on intestinal transport in normal human volunteers.

\section{Methods}

\section{VOLUNTEERS}

Eleven healthy volunteers (seven men and four women) aged between 19 and 25 years gave their informed consent for the studies. After an overnight fast the subjects were intubated with a triple lumen

Address for correspondence: Professor L A Turnberg. Department of Medicine. Hope Hospital, (University of Manchester School of Medicinc), Eccles Old Road. Salford M6 8HD.

Received for publication 10 February 1986. perfusion tube assembly as previously described. ${ }^{6}$ This tube incorporates a $10 \mathrm{~cm}$ mixing segment and a $30 \mathrm{~cm}$ test segment and the studies were carried out when the infusion port was sited at the duodenojejunal flexure. After this tube was sited a Mallinckrodt ventrol double lumen tube (FG14 or 16) was passed orally and sited in the antrum of the stomach for gastric aspiration. A fine bore infusion tube (OD $1.5 \mathrm{~mm}$ ), welded to the gastric tube, was sited with its opening $10 \mathrm{~cm}$ proximal to the aspiration holes of the main tube.

The infusion rate into the jejunum was $10 \mathrm{ml}$ per minute via a peristaltic pump and aspiration from the proximal collection site at $1.5 \mathrm{ml}$ per minute was made by a hand held syringe. Collection from the distal aspiration site was made through a low pressure suction apparatus $(1.5 \mathrm{kPa})$. Aspiration of samples from the distal port was started and finished 10 minutes later than that from the proximal port. After a 30 minute equilibration period three separate one hour collection periods were made. During the first and last hours (control and recovery periods respectively) subjects simply rested in a recumbent position. During the second hour, the sham feeding period, subjects chewed a meal consisting of $80 \mathrm{o}$ of fried steak, $9 \mathrm{oz}$ chips, $2 \mathrm{oz}$ of peas and two slices of fruit cake with $300 \mathrm{ml}$ of orange juice to rinse the mouth. Subjects were instructed to chew the food but to spit it out, before it disintegrated, into a 
beaker so that no food was swallowed. On all occasions the subjects had enough food to last the whole hour of this test period. Food was cooked in another part of the building so that subjects could neither see nor smell food in advance. Subjects were not told until the end of the control period that they would be asked to chew a meal.

Aspiration of gastric juice was continued throughout the whole of the three hours of the test via an intermittent suction pump (Ameda Ltd, Switzerland, model 17) at $6.4 \mathrm{KPa}$.

Solutions used were: (1) Jejunal perfusate contained $\mathrm{Na} 136, \mathrm{Cl} 105, \mathrm{~K} 5, \mathrm{SO}_{+} 18 \mathrm{mM}$ and polyethylene glycol 4,000,5 g/l. Included in the jejunal perfusate was $0.5 \mu \mathrm{Ci} / /$ of ${ }^{14} \mathrm{C}$ polyethylene glycol. Glucose and bicarbonate, which enhance absorption, were not used in case these masked small changes in jejunal secretion induced by sham feeding. (2) In order to calculate recovery of gastric aspirate ${ }^{3} \mathrm{H}$ polyethylene glycol $(12.5 \mu \mathrm{Ci} / \mathrm{l})$ in $\mathrm{NaCl}$ $150 \mathrm{mmol} / \mathrm{l}$ was infused by syringe pump at $1 \mathrm{ml} / \mathrm{min}$ into the mid-stomach.

Analysis of samples. An LKB Wallac S 1,000 Liquid Scintillation Counter was used to determine ${ }^{14} \mathrm{C}$ and ${ }^{3} \mathrm{H}$ in jejunal or gastric juice. Window settings on this equipment were arranged so that overlap between ${ }^{3} \mathrm{H}$ and ${ }^{1+} \mathrm{C}$ activity was minimised. Sodium and potassium concentrations were measured with a Corning 480 Flame Photometer and chloride with a Corning Chloride Analyser. Gastric aspirate acidity was measured with a Beckman Digital pH Meter, Model 3500.

Net movements of water and electrolytes were calculated using methods previously described. ${ }^{\prime}$

The percentage recoveries of gastric contents were calculated as follows:

$$
\% \text { recovery }=\frac{\begin{array}{c}
\text { Amount of radioactivity } \\
\text { aspirated }
\end{array}}{\begin{array}{c}
\text { Amount of radioactivity } \\
\text { infused }
\end{array}} \times 100
$$

that is,

$$
\% \text { recovery }=\frac{\begin{array}{c}
\text { Volume recovered } \times \text { DPM } \\
\text { in aspirate }
\end{array}}{\begin{array}{c}
\text { Volume infused } \times \text { DPM in } \\
\text { infusate }
\end{array}} \times 100
$$

The output of gastric acid for each period was adjusted for percentage recovery and calculated from the $\mathrm{pH}$ according to the method of Moore and Scarlata. $^{7}$

Results are expressed as the mean and standard error of the mean and the data from the control and sham feeding periods were compared by Student's paired $t$ test.

\section{Results}

\section{GASTRIC SECRETION}

Mean gastric acid output during the control period was $1.29 \pm 0.54 \mathrm{mmol} / \mathrm{h}$. During sham feeding there was a significant increase in acid output to $7.73 \pm 2.17 \mathrm{mmol} / \mathrm{h}(\mathrm{p}<0.02)$ (Figure 1). Two subjects did not show any rise in acid output during sham feeding and a third subject developed a small rise during the recovery hour (from 0.59 to 1.37 $\mathrm{mmol} / \mathrm{h}$ ) Compared with the control hour, mean acid output was still significantly raised during the recovery hour $(2.99 \pm 0.62, p<0 \cdot 02)$, but this was mainly due to acid secreted within the first 15 minutes following cessation of sham feeding (Figure $1)$.

\section{GASTRIC ASPIRATION}

The overall mean recovery of gastric secretion during sham feeding was $73.4 \%$ but in one subject recovery was only $13.3 \%$ and the mean value in the remainder was $79.4 \%$. Compared with the control hour there was no significant difference during sham feeding in the calculated flow rate at the proximal jejunal collection site (Mean difference $4 \cdot 3 \%$ ). The mean $\mathrm{pH}$ of proximal jejunal fluid was $7 \cdot 2 \pm 0 \cdot 16$ in the control period and $7 \cdot 1 \pm(0 \cdot 16$ during sham feeding. In all subjects the gastric aspirate was free of food.

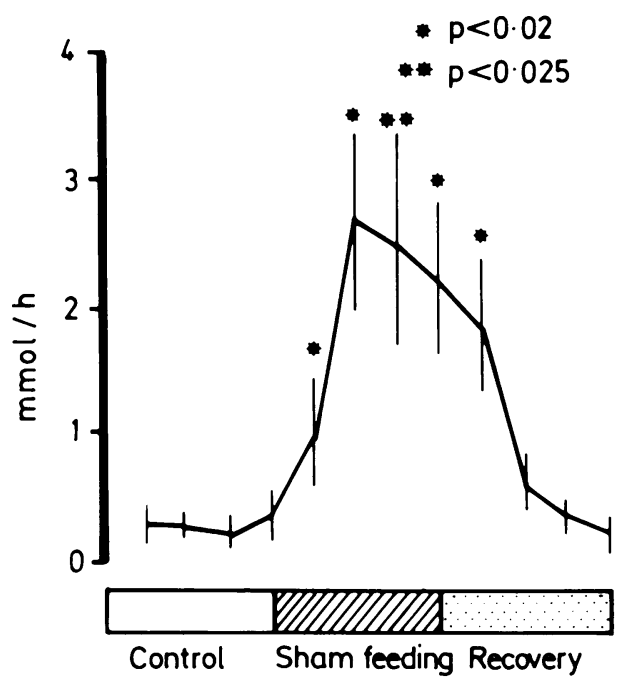

Fig. 1 Gastric acid secretion during a control period, during sham feeding and after sham feeding. Mean acid secretion rates during consecutive 15 minute periods are shown and standard errors of the mean indicated $(n=10)$. In one other subject acid secretion rates were not measured in separate 15 minute periods. 
JEJUNAL TRANSPORT

Individual results are shown in Figure 2 and mean results in the Table. These show a small, but significant, reduction in mean water, sodium, chloride and potassium absorption during sham feeding.

During the recovery period mean water and electrolyte absorption returned towards the control values.

There was no statistical correlation between the effects of sham feeding on acid secretion and on jejunal transport, nor between the calculated mmol of gastric acid lost from the stomach and jejunal absorption.
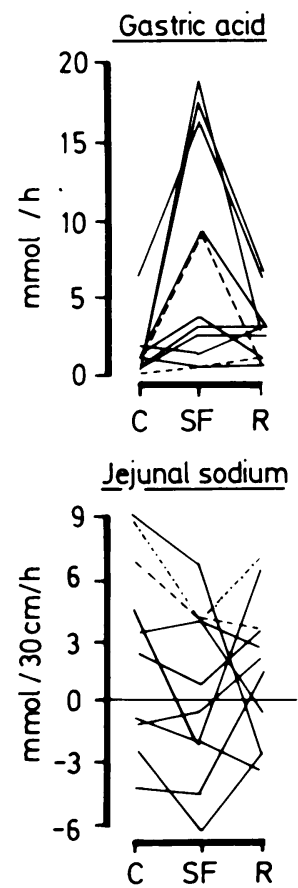

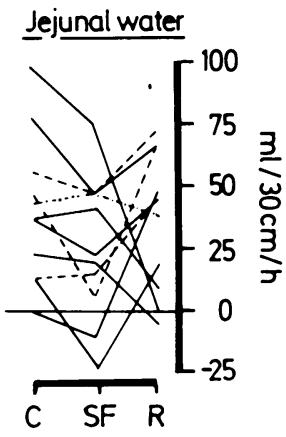

Jejunal chloride

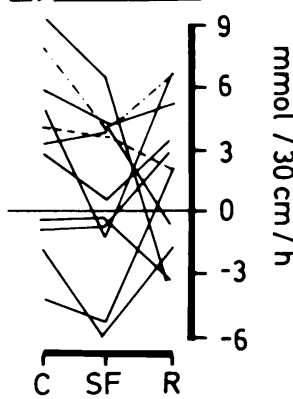

Fig. 2 Changes in gastric acid secretion ( $m$ mol/h) and water, sodium and chloride transport in the jejunum $(\mathrm{ml} / \mathrm{h}$ and $\mathrm{mmol} / \mathrm{h}$ ) during a control $(C)$, sham feeding $(S F)$ and recovery $(R)$ period. Results from each individual study are shown $(n=I I)$ ( + ve values indicate net absorption, -ve values, net secretion).

Table Mean and SEM of jejunal water and electrolyte transport

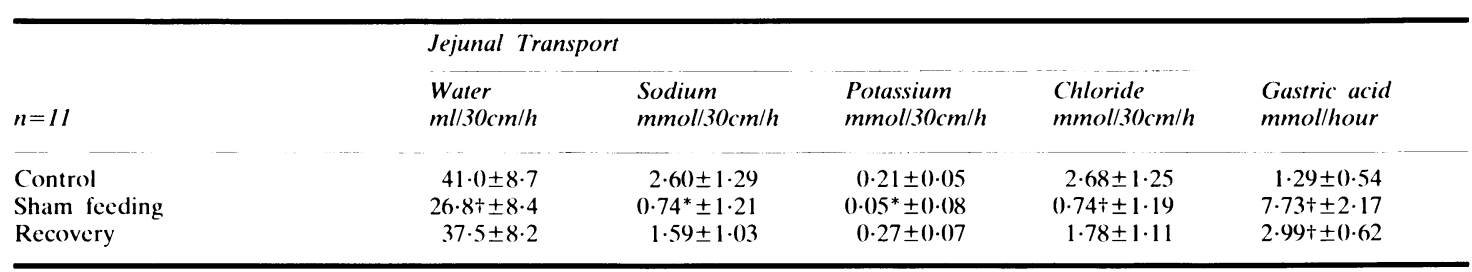

Several pieces of evidence suggest that the autonomic nervous system influences intestinal absorption. Section of the sympathetic nerves to loops of cat intestine in vivo was associated with intestinal secretion which could be blocked by atropine. Studies of isolated pieces of small intestinal mucosa from mammalian species, including man, have shown that acetyl choline stimulates a secretion which is inhibited by atropine suggesting that muscarinic receptors are involved in this response. ${ }^{1}$ Furthermore cholinergic receptors have been demonstrated on intestinal epithelial cells. ${ }^{4}$ Alpha 2 adrenergic agonists enhance absorption in the small intestine $^{9-11}$ and adrenergic binding receptors have been demonstrated on intestinal epithelial cells too. ${ }^{5}$

In the human jejunum and ileum in vivo earlier work from our laboratory showed that cholinergic agonists reduced absorption while atropine enhanced absorption. ${ }^{2}$ These observations suggested that not only could cholinergic agonists influence transport but that some tonic cholinergic effect might have influenced basal transport which was revealed by atropine. Similar in vivo perfusion studies showed that the beta agonist isoproterenol enhanced absorption and that the beta blocker propanolol inhibited absorption providing similar evidence that adrenergic agents can influence absorption in vivo too. ${ }^{3}$

Unfortunately these studies merely show that exogenous agonists and antagonists are capable of influencing intestinal transport but they tell us little of the potential for a physiological role for the autonomic nervous system in the control of intestinal intestinal mucosal function. The current studies are thus of some interest in this regard. Sham feeding is a well recognised method of stimulating the vagus nerve. ${ }^{12} 13$ That it was effective in our studies was shown by the response of gastric acid secretion. Although the response was modest it was nevertheless clear cut in most individuals.

It is noteworthy that jejunal absorption of water, 
sodium, chloride and potassium were significantly reduced by sham feeding. This observation is compatible with a vagally induced cholinergic effect on mucosal transport. There are of course several ways in which sham feeding might influence intestinal transport via vagal stimulation. Firstly acid escaping from the stomach may have influenced transport. Acid secretion rates, however, were low during stimulation and the mean recovery of gastric contents (almost $80 \%$ ) suggests that very little acid would have escaped into the upper intestine. Furthermore, the mean proximal jejunal flow rate during the control and sham feeding periods differed by less than $5 \%$, the mean $\mathrm{pH}$ values were not significantly different and there was no correlation between the calculated gastric acid lost from the stomach and changes in jejunal absorption. Secondly it is conceivable that vagal stimulation influenced secretion from the pancreas or biliary tree and that these secretions secondarily influenced transport. This seems unlikely as an alkaline secretion entering the jejunal segment is more likely to have enhanced absorption than reduced it. Thirdly changes in intestinal motility may result from vagal stimulation and this effect may secondarily influence transport. Although this source of potential error cannot be excluded it seems unlikely to be relevant because earlier studies with exogenous cholinergic and anticholinergic agents detected no correlation between motility and transport effects of these agents. ${ }^{2}$ It is also possible that vagal stimulation liberated one or more neuropeptides or paracrine secretion which may then have influenced transport.

Despite these considerations our observations, taken together with previous studies of the influence of cholinergic agonists and antagonists, support the hypothesis that the parasympathetic division of the autonomic nervous system does influence intestinal transport under physiological conditions and may do so by a direct effect on cholinergic receptors in the epithelium.

Similar sham feeding studies in man were done by Read and Fordtran but they concluded that intestinal transport was unaffected. ${ }^{14} \mathrm{~A}$ close examination of their data, however, revealed that in four of their seven healthy subjects and in two of their three subjects with achlorhydria absorption was reduced or secretion occurred during the sham feeding period. Thus there was a similar trend to that reported in the paper but the greatly increased absorption of one healthy subject and one with achlorhydria clearly modified the mean responses.

We conclude that as sham feeding appeared to influence jejunal absorption of salt and water in man, that the autonomic innervation of the small intestine may have a physiological role in the control of intestinal absorption.

The authors wish to thank L Hall and N Higgs for their technical assistance.

\section{References}

1 Isaacs PET, Corbett CL, Riley AK, Hawker PC, Turnberg LA. In vitro behaviour of human intestinal mucosa. The influence of acetylcholine on ion transport. J Clin Invest 1976; 58: 535-42.

2 Morris AI, Turnberg LA, Hall L, Pimblett K. The influence of a parasympathetic agonist and antagonist on human intestinal transport in vivo. Gastroenterology 1980; 79: 861-6.

3 Morris AI, Turnberg LA. Influence of isoproterenol and propranolol on human intestinal transport in vivo. Gastroenterology 1981; 81: 1076-9.

4 Isaacs PET, Whitehead JS, Kim YS. Muscarinic acetylcholine receptors of the small intestine and pancreas of the rat: distribution and the effect of vagotomy. Clin Sci 1982; 62: 203-7.

5 Chang EB, Field M, Miller RJ. Enterocyte alpha 2-adrenergic receptors: yohimbine and $\mathrm{p}$ aminoclonidine binding relative to ion transport. $A m$ J Physiol 1983; 244: G76-G82.

6 Cooper H, Levitan R, Fordtran JS, Ingelfinger FJ. A method for studying absorption of water and solutes from the human small intestine. Gastroenterology, 1966; 50: $1-7$.

7 Moore GW, Scarlata RW. The determination of gastric acidity by the glass electrode. Gastroenterology 1965 ; 49: 178-88.

8 Wright RD, Jennings MA, Florey HW, Lium R. The influence of nerves and drugs on secretion by the small intestine and an investigation of the enzymes in intestinal juice. $Q J$ Exp Physiol 1940; 30: 73-120.

9 Field M, McColl I. Ion transport in rabbit ileal mucosa. III. Effects of catecholamines. Am J Physiol 1973; 225: 852-7.

10 Tapper EJ, Bloom AS, Lewand DL. Endogenous norepinephrine release induced by tyramine modulate intestinal ion transport. Am J Physiol 1981; 241 (Gastrointest Liver Physiol 4): G264-G269.

11 Chang EB, Field M, Miller RJ. $\alpha_{2}$-adrenergic receptor regulation of ion transport in rabbit ileum. Am J Physiol 1982; 242 (Gastrointest Liver Physiol 5): G237-G242.

12 Mayer G, Arnold R, Fuerle G, Fuchs HK, Ketterer H, Tracak NS, Creutzfelt W. Influence of feeding and sham feeding upon serum gastrin and gastric acid secretion in control subjects and duodenal ulcer patients. Scand J Gastroenterol 1974; 9: 703-10.

13 Richardson CT, Walsh JH, Cooper KA, Feldman M, Fordtran JS. Studies on the role of cephalic-vagal stimulation in the acid secretory response to eating in normal human subjects. J Clin Invest 1977; 60: 435-41.

14 Read NW, Cooper K, Fordtran JS. Effect of modified sham feeding on jejunal transport and pancreatic and biliary secretion in man. Am J Physiol 1978; 234: E417-20. 